\title{
Regulation of the sulfate starvation response in Pseudomonas aeruginosa: role of cysteine biosynthetic intermediates
}

\author{
Jörg Hummerjohann, ${ }^{1}$ Erika Küttel, ${ }^{1}$ Manfredo Quadroni, ${ }^{2}$ \\ Jürgen Ragaller, ${ }^{1}$ Thomas Leisinger ${ }^{1}$ and Michael A. Kertesz ${ }^{1}$
}

Institutes of Microbiology 1 and Biochemistry'2, Swiss Federal Institute of Technology, $\mathrm{CH}-8092$ Zürich, Switzerland Author for correspondence: Michael A. Kertesz. Tel: +41 163233 57. Fax: +41163211 48.
e-mail: kertesz@micro.biol.ethz.ch

\begin{abstract}
Pseudomonas aeruginosa PAO1 grew in defined synthetic medium with any of a broad variety of single sulfur sources, including sulfate, cysteine, thiocyanate, alkanesulfonates, organosulfate esters and methionine, but not with aromatic sulfonates, thiophenols or organothiocyanates or isothiocyanates. During growth with any of these compounds except sulfate, cysteine or thiocyanate, a set of 10 sulfate starvation-induced (SSI) proteins was strongly up-regulated, as observed by two-dimensional protein electrophoresis of total cell extracts. A comparable level of up-regulation was found for the hydrolytic enzyme arylsulfatase, which has previously been used as a marker enzyme for the sulfate starvation response. One of the SSI proteins was identified by $\mathbf{N}$-terminal sequencing as a high-affinity periplasmic sulfate-binding protein, and another was related to thiol-specific antioxidants, but the $\mathrm{N}$-terminal sequences of the other SSI proteins revealed no similarity to $\mathbf{N}$-termini of proteins of known function, and they probably represent uncharacterized enzymes involved in sulfur scavenging when preferred sulfur sources are absent. To study the role that cysteine biosynthetic intermediates play in the synthesis of these proteins in vivo, we isolated mini-Tn5 transposon mutants of $P$. aeruginosa with insertions in the cys $N$ and cysl genes, which encode subunits of ATP-sulfurylase and sulfite reductase, respectively. These two genes were cloned and sequenced. cysl showed high similarity to the cognate gene in Escherichia coli, whereas CysN encoded a $69.3 \mathrm{kDa}$ protein with two domains corresponding to the $E$. coli CysN and CysC proteins. Sulfate no longer repressed synthesis of the SSI proteins in CysN mutants, but repression was restored by sulfite; in the cysi mutant, sulfate, sulfite and sulfide all led to repression of SSI protein synthesis. This suggests that there are at least two independent corepressors of the sulfate starvation response in this species.
\end{abstract}

Keywords: Pseudomonas aeruginosa, sulfate starvation, cysteine biosynthesis

\section{INTRODUCTION}

Cysteine biosynthesis by the sulfate assimilation pathway has been well-characterized in both plants and micro-organisms (Kredich, 1996; Leustek, 1996). It

Abbreviations: SSI, sulfate starvation-induced; SSIS, sulfate starvationinduced stimulon.

The GenBank accession numbers for the sequences reported in this paper are AF026066 (cysi) and AF035608 (cysDN). proceeds by activation of inorganic sulfate, followed by reduction of the intermediate phosphoadenosyl phosphosulfate to sulfite and hence to sulfide, and transfer of this molecule onto an organic backbone. In limnic and enteric environments, sulfate is present in excess of microbial requirements, but in aerobic soils sulfur is available almost exclusively $(>95 \%$ ) in organically bound form, and inorganic sulfate is rare (Autry \& Fitzgerald, 1990). The sulfur pool in the soil is, in addition, a dynamic one. Isotopic studies with ${ }^{35} \mathrm{~S}$ have shown not only that inorganic sulfate is rapidly in- 
corporated into soil organic matter (Strickland et al., 1986), but that soil organic sulfur (which may be present as sulfate ester-sulfur, amino acid/protein-sulfur or sulfonate-sulfur) is also cycled between forms (Watwood et al., 1986). This cycling is assumed to be due to microbial activity in the soil, or to microbially released soil enzymes, but the mechanisms involved in sulfur soil cycling and in the response of soil bacteria to sulfate limitation are not yet well understood.

For Escherichia coli, in contrast, the response to sulfur limitation has been studied in some detail. When this species is grown with sulfonate-sulfur as sulfur source, in the absence of inorganic sulfate, a set of proteins is synthesized which is completely absent during growth in the presence of inorganic sulfate (Quadroni et al., 1996; van der Ploeg et al., 1996). These proteins include a taurine sulfonatase (Eichhorn et al., 1997), high-affinity uptake systems for sulfate and cystine, and several unidentified proteins. The proteins induced by sulfate starvation in $E$. coli therefore appear to be 'sulfurscavenging enzymes' involved in utilization of nonfavoured sulfur sources.

In soil environments, such bacterial 'sulfur-scavenging enzymes' may be critically important in the in situ degradation of sulfur-containing xenobiotics. Desulfonation of a broad range of aromatic sulfonates, which are released into the environment in large quantities each year as, for example, detergents and dyestuffs, has been demonstrated in several soil isolates (Dudley \& Frost, 1994; Kertesz et al., 1994; Zürrer et al., 1987). Synthesis of the enzyme responsible is strongly repressed in the presence of sulfate or cysteine (Beil et al., 1996). Similar results have been obtained for the desulfurization of dibenzothiophene by Rbodococcus species, as part of studies aimed at biodesulfurization of coal and oil (Kayser et al., 1993). Another well-characterized sulfurscavenging enzyme is the hydrolytic enzyme arylsulfatase, which releases sulfate from aromatic sulfate esters, and is one of the commonest enzymes found in soil. Synthesis of this enzyme is repressed by sulfate in pseudomonads (Beil et al., 1995; Kertesz et al., 1993) and in other bacterial and fungal species (Dodgson et al., 1982).

In the present study, we have investigated the regulation of the sulfate starvation response in a ubiquitous soil bacterium, Pseudomonas aeruginosa. We report here that $P$. aeruginosa responded to sulfate limitation with the synthesis of at least 10 novel proteins, and that expression of the corresponding genes was mediated by at least two separate corepressors.

\section{METHODS}

Chemicals. Sulfur-containing chemicals used as sulfur sources for bacterial growth were of the highest purity commercially available, and were obtained from Fluka, except for 4phenylbutane sulfonate and $n$-hexyl sulfate (Aldrich). The sulfate content of all sulfur sources was checked by ion chromatography before use (Kertesz et al., 1994) and was found to be less than $0.5 \mathrm{~mol} \%$. DNase I and RNase A were from Boehringer Mannheim. Ampholyte mixtures ( $\mathrm{pH} 3-10$ ) for two-dimensional PAGE were obtained from Bio-Rad. Oligonucleotides were supplied by Microsynth.

Bacterial strains, media and growth conditions. Bacterial strains used in this study are listed in Table 1 . $P$. aeruginosa strains were routinely cultivated in the sulfur-free succinate salts medium described previously (Kertesz et al., 1993), with the addition of all the naturally occurring protein amino acids $\left(40 \mu \mathrm{g} \mathrm{ml}^{-1}\right)$, except methionine and cysteine. Sulfur-limited solid media were prepared by addition of $0.6 \%$ molecular biology grade agarose (FMC BioProducts). Sulfur sources $(500 \mu \mathrm{M})$ were added as described in the text. All glassware used in sulfate-limited experiments was washed with $3 \mathrm{M} \mathrm{HCl}$ and rinsed thoroughly with glass-distilled water before use. Cultures were grown either aerobically on a rotary shaker (180 r.p.m.) $\left(30 \mathrm{ml}\right.$ cultures in $300 \mathrm{ml}$ flasks) at $37^{\circ} \mathrm{C}$, or in a vigorously stirred, flat-bottomed $500 \mathrm{ml}$ flask held in a thermostat-controlled water bath at $37^{\circ} \mathrm{C}$, with a continuous air supply (Harvey et al., 1968). Growth was monitored spectrophotometrically at $650 \mathrm{~nm}$, and the cells were harvested in the mid-exponential phase. Growth rates were determined by measuring total protein in samples removed from the cultures during growth (Beil et al., 1996). Antibiotics were added at the following concentrations $\left(\mathrm{ml}^{-1}\right)$ : ampicillin, $100 \mu \mathrm{g}$ for E. coli; tetracycline, $25 \mu \mathrm{g}$ for E. coli and $125 \mu \mathrm{g}$ for $P$. aeruginosa; streptomycin and carbenicillin, $500 \mu \mathrm{g}$ for $P$. aeruginosa.

Two-dimensional protein gel electrophoresis, protein extraction and sequencing. $P$. aeruginosa cells were prepared for two-dimensional gel electrophoresis by lysis with SDS followed by incubation with urea/CHAPS/DTT by the method of Hochstrasser et al. (1988). For analytical gels ( $1.0 \mathrm{~mm}$ thickness), 5-20 $\mathrm{\mu g}$ protein was loaded, and the separated proteins were visualized by silver staining (Ausubel et al., 1987). Preparative gels were thicker $(1.5 \mathrm{~mm})$, and up to $300 \mu \mathrm{g}$ protein was loaded. Isoelectric focusing was carried out in tube gels with carrier ampholytes for $16 \mathrm{~h}$ at $500 \mathrm{~V}$. The tube gels were then equilibrated in transfer buffer $(70 \mathrm{mM}$ Tris $/ \mathrm{HCl}, 3.0 \%$ SDS, $0.003 \%$ bromophenol blue, $\mathrm{pH} 6.8$ ) for approximately $2 \mathrm{~min}$ before transfer onto a $12 \%$ polyacrylamide second-dimension gel. Isoelectric focusing and SDS-PAGE were both done with the Protean 2-D PAGE apparatus (Bio-Rad). For analysis purposes, the gels were scanned with a Personal Densitometer (Molecular Dynamics), and image analysis and spot matching were carried out with the Investigator software package (Millipore). Isoelectric points and molecular masses were determined by co-electrophoresis with a set of $2-\mathrm{D}$ protein standards (Bio-Rad). For preparative purposes, individual proteins from 10-20 gels were excised, concentrated as described previously by Hatt $e t$ al. (1997), and blotted onto PVDF membrane. The N-terminal sequence was determined by automated Edman degradation (Applied Biosystems 120A PTH Sequenator).

Enzyme assays and preparation of cell extracts. Cell extracts for enzyme assays were prepared from cells harvested in the mid-exponential growth phase. The cells were harvested $\left(7000 \mathrm{~g}, 15 \mathrm{~min}, 4^{\circ} \mathrm{C}\right)$, washed and treated with lysozyme ( $\left.1 \mathrm{mg} \mathrm{ml}^{-1}, 60 \mathrm{~min}\right)$, and then lysed by three passages through a chilled French pressure cell at $135 \mathrm{MPa}$. Cell debris and membranes were removed by ultracentrifugation $(250000 \mathrm{~g}$, $30 \mathrm{~min}, 4^{\circ} \mathrm{C}$ ). The cell extract was then desalted by passage over a small Sephadex G-25 column (PD-10; Pharmacia). When necessary, the extract was stored at $-20^{\circ} \mathrm{C}$ before assaying enzyme activities; however, cystathionine $\beta$-lyase was always assayed immediately, as it proved to be unstable to freezing.

Arylsulfatase was assayed in whole cells or cell extracts as 
Table 1. Bacterial strains and plasmids used in this study

\begin{tabular}{|c|c|c|}
\hline Strain/plasmid & Genotype/relevant features & Reference/source \\
\hline \multicolumn{3}{|l|}{ P. aeruginosa } \\
\hline PAO1 & Prototroph & Holloway (1955) \\
\hline PAO1S & Spontaneous streptomycin-resistant mutant of PAO1 & Beil et al. (1995) \\
\hline PAO716 & cys54 rif96 & $\begin{array}{l}\text { Ratnaningsih et al. } \\
\text { (1990) }\end{array}$ \\
\hline PAO1219 & $\operatorname{trp} 54$ cys $50:: \operatorname{Tn} 5$ rif5 fon 1 & $\begin{array}{l}\text { B. Holloway, Monash } \\
\text { University, Australia }\end{array}$ \\
\hline AC309 & cys $N:: \operatorname{mini}-\mathrm{Tn} 5-\mathrm{Tc}$ & This study \\
\hline AX18 & $c y s I:: \operatorname{mini}-\mathrm{Tn} 5-\mathrm{Tc}$ & This study \\
\hline \multicolumn{3}{|l|}{ E. coli } \\
\hline DH5 $\alpha$ & supE44 $\Delta l a c \mathrm{U} 169$ ( $\phi 80$ lacZuM15) bsdR recA1 endA1 gyrA96 thi-1 relA1 & Hanahan (1983) \\
\hline S17-1 $\lambda$ pir & $\begin{array}{l}\text { hsdR thi pro recA; RP4 integrated into the chromosome (kan:: } \operatorname{Tn} 7 \text { ter::Mu) } \\
\quad \text { apir }\end{array}$ & $\begin{array}{l}\text { De Lorenzo \& Timmis } \\
\text { (1994) }\end{array}$ \\
\hline \multicolumn{3}{|l|}{ Plasmid } \\
\hline pBluescript II KS & Cloning vector, $\mathrm{Amp}^{\mathrm{R}}$ & Stratagene \\
\hline pLAFR3 & IncP-1, cos, Tra, $\mathrm{Tc}^{\mathrm{R}}$ & Staskawicz et al. (1987) \\
\hline pUT-mini-Tn5-Tc & Delivery vector for mini-Tn5-Tc & $\begin{array}{l}\text { De Lorenzo \& Timmis } \\
\text { (1994) }\end{array}$ \\
\hline pME4007 & pLAFR3-derived cosmid clone from $P$. aeruginosa including the $c y s D N$ genes & This study \\
\hline pME4008 & pLAFR3-derived cosmid clone from $P$. aeruginosa including the cysI gene & This study \\
\hline pME4062 & $3.8 \mathrm{~kb}$ Pst $\mathrm{I}-\mathrm{X} h o \mathrm{I}$ fragment $\left(\mathrm{Tc}^{\mathrm{R}}\right)$ ex strain AX18, in pBluescript $\mathrm{KS}$, cysI & This study \\
\hline pME4311 & $3.3 \mathrm{~kb}$ PstI fragment $\left(\mathrm{Tc}^{\mathrm{R}}\right)$ from strain AC309 in pBluescript SK, cysDN & This study \\
\hline pME4318 & $1.8 \mathrm{~kb}$ NotI-StuI fragment $\left(\mathrm{Tc}^{\mathrm{R}}\right)$ from strain $\mathrm{AC} 309$ in pBluescript $\mathrm{SK},{ }^{\prime} c y s N$ & This study \\
\hline
\end{tabular}

release of 4-nitrocatechol from 4-nitrocatechol sulfate as described previously (Beil et al., 1995; Kertesz et al., 1993). Rhodanese was assayed as thiocyanate production (Westley, 1981). Cystathionine $\beta$-lyase was measured by the method of Uren (1987), and cystathionine $\gamma$-lyase was assayed as 2oxobutanoic acid formation from $L$-homoserine (Nagasawa $e t$ al., 1987).

DNA manipulations. Molecular genetic methods were carried out using published methods (Ausubel et al., 1987). Competent $E$. coli cells for transformation were prepared by the method of Inoue et al. (1990), and P. aeruginosa cells were transformed by electroporation, using $0.1 \mathrm{~cm}$ cuvettes in a Gene Pulser apparatus (Bio-Rad). Conjugative transfers were carried out by patch mating on nutrient plates at $37^{\circ} \mathrm{C}$.

Isolation of cysteine auxotrophic mini-Tn5 mutants of $\boldsymbol{P}$. aeruginosa. Transposon mutagenesis of $P$. aeruginosa was carried out using the mini-Tn5 system (De Lorenzo \& Timmis, 1994). The transposon was introduced into $P$. aeruginosa by plate conjugation at $37^{\circ} \mathrm{C}$ for $8-24 \mathrm{~h}$, using late-exponentialphase cultures of $P$. aeruginosa PAO1S. E. coli S17-1 ipir (pUT-mini-Tn5-Tc) was used as donor strain. To screen for cysteine auxotrophy, tetracycline-resistant colonies which grew on proline-free minimal plates with cysteine as sulfur source were picked to minimal plates with either inorganic sulfate or cysteine as sulfur source $(250 \mu \mathrm{M})$. Colonies showing no growth with sulfate after $24 \mathrm{~h}$ were tested further in liquid media.

Cloning of the cysl and cysDN genes. The interrupted genes in cysteine auxotrophic strains AX18 and AC 309 were cloned by transposon rescue techniques. Suitably sized transposoncontaining DNA fragments from strains AX18 and AC309 were identified by Southern analysis using the tet gene as probe, and were then cloned into linearized pBluescript to give the plasmids pME4062, pME4311 and pME4318, respectively. After subcloning, the DNA sequences of the regions immediately flanking the transposon were determined using a primer specific for the mini-Tn5 (mkomega: $5^{\prime}$-cttgctcaatcaatcacc- $3^{\prime}$ ), and the sequences obtained were used to design oligonucleotides for PCR-based screening of a cosmid library of $P$. aeruginosa (Visca et al., 1994). Cosmids containing the cysl and cysDN genes (pME4008 and pME4007, respectively) were isolated, subcloned into pBluescript and the genes of interest were sequenced, using sequence-specific primers and a primer-walking strategy.

DNA sequence analysis. DNA sequences were determined on both strands using the dideoxy chain-termination method (Sanger et al., 1977). Analysis of DNA and protein sequences was done with the Genetics Computer Group Package of the University of Wisconsin, version 8 .

Other procedures. Total protein in cell suspensions was determined by a modified Lowry method (Kennedy \& Fewson, 1968 ), and soluble protein was measured with the Bio-Rad protein reagent, following the manufacturer's instructions. Bovine serum albumin was used as standard in both cases.

\section{RESULTS}

\section{Growth of $P$. aeruginosa PAO1S with different sulfur sources}

Cells of $P$. aeruginosa PAO1S grew aerobically in a synthetic sulfur-free medium with sulfur for growth supplied either as inorganic sulfate, or as one of a range of different, non-sulfate sulfur sources (Table 2). 
Table 2. Growth rates and selected enzyme activities observed during growth with sulfur sources used in this study

Relative enzyme activities were determined in extracts from cells harvested in the mid-exponential growth phase $\left(O D_{650} 0 \cdot 8\right)$. They were assayed as described in Methods, and represent three independent experiments. Activities are normalized to the activity observed after growth with sulfate. Typical values seen with sulfate were: arylsulfatase, $0.84 \mathrm{nmol} \mathrm{min} \mathrm{mg}^{-1} \mathrm{mg}^{-1} \mathrm{rhodanese}^{-}$ $130 \mu \mathrm{mol} \mathrm{min}-1 \mathrm{mg}^{-1}$; cystathionine $\gamma$-lyase, $1.83 \mathrm{nmol} \mathrm{min}{ }^{-1} \mathrm{mg}^{-1}$; cystathionine $\beta$-lyase, $0.16 \mathrm{nmol} \mathrm{min}^{-1} \mathrm{mg}^{-1}$.

\begin{tabular}{|c|c|c|c|c|c|c|}
\hline $\begin{array}{l}\text { Sulfur source for } \\
\text { growth }(500 \mu \mathrm{M})\end{array}$ & $\begin{array}{l}\text { Doubling } \\
\text { time }(\mathrm{min})^{*}\end{array}$ & $\begin{array}{c}\text { SSI } \\
\text { response } †\end{array}$ & Arylsulfatase & Rhodanese & $\begin{array}{c}\text { Cystathionine } \\
\gamma \text {-lyase }\end{array}$ & $\begin{array}{c}\text { Cystathionine } \\
\beta \text {-lyase }\end{array}$ \\
\hline Sulfate & 42 & - & $1 \cdot 0$ & $1 \cdot 00$ & $1 \cdot 00$ & $1 \cdot 00$ \\
\hline Thiocyanate & 50 & - & $3 \cdot 5$ & $1 \cdot 22$ & $1 \cdot 10$ & $1 \cdot 13$ \\
\hline Cysteine & 79 & - & $12 \cdot 0$ & $0 \cdot 84$ & $2 \cdot 43$ & $2 \cdot 19$ \\
\hline Methionine & 88 & + & $57 \cdot 0$ & $1 \cdot 16$ & $3 \cdot 49$ & $2 \cdot 56$ \\
\hline Cystine & 78 & + & $18 \cdot 0$ & $1 \cdot 20$ & $2 \cdot 64$ & $2 \cdot 31$ \\
\hline$n$-Hexyl sulfate & 61 & + & $35 \cdot 0$ & 0.93 & $1 \cdot 77$ & $3 \cdot 81$ \\
\hline 4-Nitrocatechol sulfate & 45 & + & $45 \cdot 0$ & $1 \cdot 04$ & 3.59 & $4 \cdot 00$ \\
\hline Ethanesulfonate & 55 & + & $36 \cdot 0$ & 0.95 & $2 \cdot 26$ & $3 \cdot 88$ \\
\hline Pentanesulfonate & 57 & + & $41 \cdot 0$ & 0.92 & 1.96 & 1.69 \\
\hline Cyclohexylsulfamate & 74 & + & $67 \cdot 0$ & 0.89 & $2 \cdot 23$ & $3 \cdot 81$ \\
\hline SDS & 56 & + & $43 \cdot 0$ & 0.95 & $1 \cdot 62$ & $1 \cdot 81$ \\
\hline
\end{tabular}

*Growth rates were measured during cultivation in vigorously stirred flasks with continuous air supply (Harvey et al., 1968) for all substrates except methionine. Growth rate with methionine was measured in shaken flasks, due to rapid oxidation of the methionine under the former conditions.

†The presence or absence of an SSI response was determined by inspection of two-dimensional gels prepared with cells grown with the respective sulfur source.

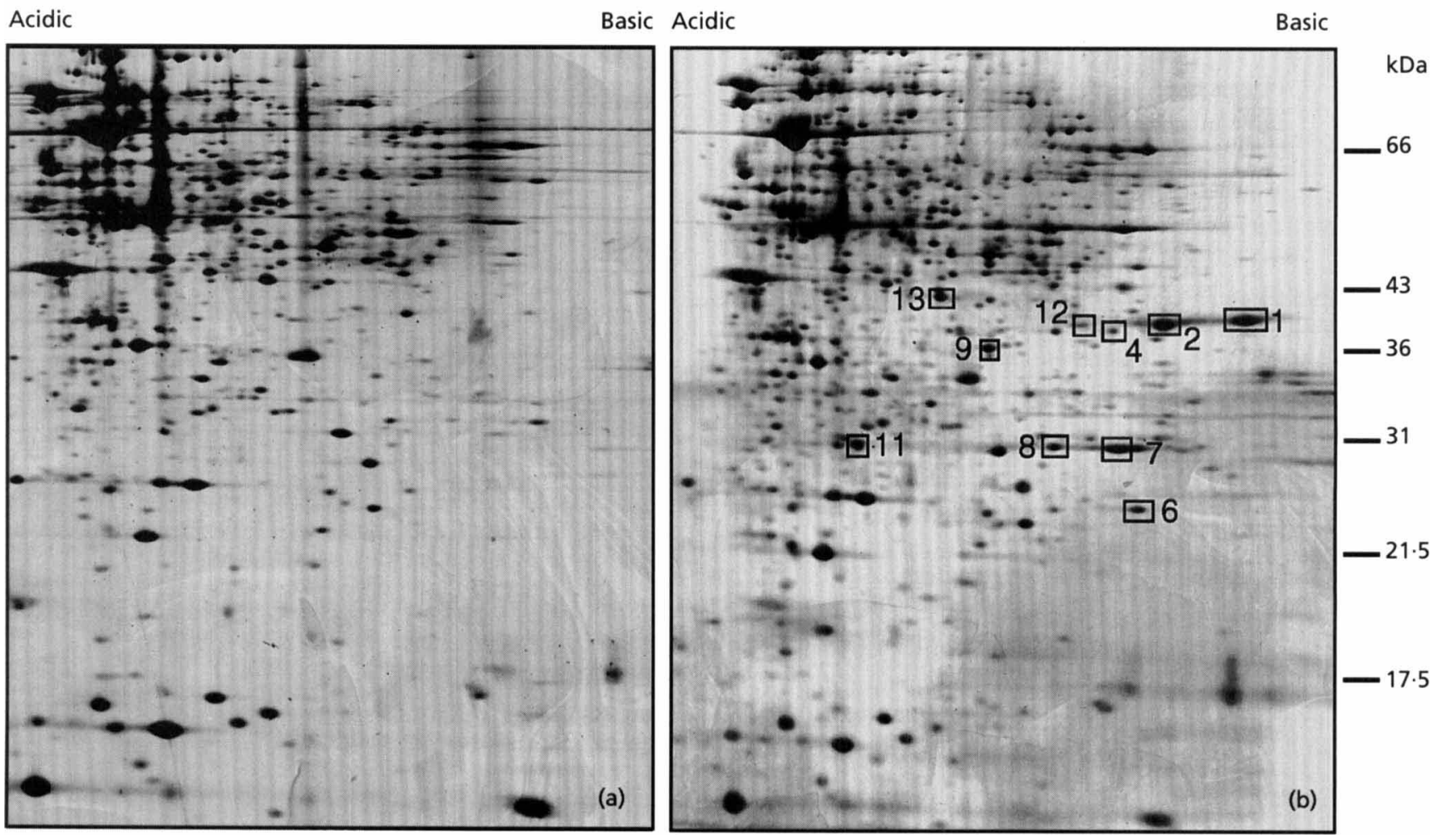

Fig. 1. Two-dimensional electropherograms of total cell protein from $P$. aeruginosa PAO1S grown aerobically in succinate salts medium with different sulfur sources: (a) sulfate, cysteine or thiocyanate; (b) other sulfur sources from Table 2 . The numbers indicate proteins that are up-regulated under sulfate starvation conditions (SSI proteins; Table 3). 
Table 3. SSI proteins in P. aeruginosa PAO

SSI proteins were identified by computer-assisted comparison of silver-stained two-dimensional gels. For preparative purposes proteins were extracted from cells grown with sulfate or with ethanesulfonate as sulfur source, and were purified and analysed as described in Methods. Protein numbering corresponds to that in Fig. 1. The results are representative of three independent experiments.

\begin{tabular}{|c|c|c|c|c|c|}
\hline Protein & $\begin{array}{l}\text { Mol. mass } \\
(\mathrm{kDa})\end{array}$ & $\mathrm{pI}$ & $\begin{array}{l}\text { Up-regulation } \\
\text { (-fold })^{*}\end{array}$ & $\begin{array}{c}\text { N-terminal amino acid } \\
\text { sequence } \dagger\end{array}$ & Comments \\
\hline PA1 & $38 \cdot 8$ & $6 \cdot 70$ & $4 \cdot 8$ & ATQLLNVSYDPTXE & Sulfate-binding protein \\
\hline PA2 & $38 \cdot 8$ & $6 \cdot 30$ & $2 \cdot 6$ & XEQSANTLRIXYQRYXXLV & No similarity found \\
\hline PA4 & $37 \cdot 5$ & $6 \cdot 20$ & SSI & XNAAQALAVPVRLDIYP & No similarity found \\
\hline PA6 & $23 \cdot 8$ & $6 \cdot 30$ & $6 \cdot 2$ & - & $\begin{array}{l}\text { Not Coomassie-blue- } \\
\text { detectable }\end{array}$ \\
\hline PA7 & $28 \cdot 0$ & $6 \cdot 25$ & $2 \cdot 2$ & AEKLIVAATPIPHAEILELIKPTLA & No similarity found \\
\hline PA8 & $28 \cdot 0$ & $6 \cdot 00$ & $2 \cdot 6$ & - & N-terminally blocked \\
\hline PA9 & $36 \cdot 4$ & $5 \cdot 80$ & SSI & ADITVGYQTGIDPXK & No similarity found \\
\hline PA11 & $28 \cdot 0$ & $5 \cdot 65$ & $5 \cdot 0$ & SLRLGDIAPDFEQD & $\begin{array}{l}\text { Similarity to liver spot } 40 \\
\text { (Hochstrasser } \text { et al., 1993) }\end{array}$ \\
\hline PA12 & $38 \cdot 8$ & $6 \cdot 05$ & SSI & XQGALMXQP & No similarity found \\
\hline PA13 & $44 \cdot 5$ & $6 \cdot 00$ & SSI & XLEIFAFLPTHGD & $\begin{array}{l}\text { Similarity to OrfM } \\
\text { (Quirk et al., 1994) }\end{array}$ \\
\hline
\end{tabular}

* SSI indicates that proteins were not visible by silver staining after growth with sulfate, cysteine or thiocyanate.

$\dagger \mathrm{X}$ indicates amino acid residues which could not be assigned with certainty.

Growth yields in this medium were found to be limited by sulfur when the sulfur concentration was below $120 \mu \mathrm{M}$ (not shown), and since we wished to examine the bacterial response to sulfate limitation but not total sulfur deprivation, we always supplied excess sulfur $(500 \mu \mathrm{M})$. $P$. aeruginosa proved quite flexible in the range of sulfur-containing compounds which it could utilize for growth. The cells were able to grow well on all the sulfur sources listed in Table 2, and these were therefore used in subsequent experiments for analysis of the SSI response. $P$. aeruginos $a$ was also able to utilize all alkanesulfonates tested (including, amongst others, 4phenylbutanesulfonate, taurine, ethanesulfonate, MOPS, HEPES, bromoethanesulfonate), as well as aromatic and aliphatic sulfate esters, thiosulfate, glutathione, thioglycollate, isethionate and dimethylsulfoxide. No utilization of aromatic sulfonates such as toluenesulfonate, aromatic sulfides such as dibenzothiophene, aromatic thiols such as thiocresol, or organic thiocyanates or isothiocyanates was observed, though control experiments showed that these compounds were not toxic at the concentrations used $(500 \mu \mathrm{M})$. The doubling times observed with a variety of sulfur sources (Table 2) lay between 40 and $80 \mathrm{~min}$, but no correlation was found between synthesis of the SSI proteins and the relative growth rates observed for each sulfur source.

\section{Sulfate starvation-induced (SSI) proteins of $P$. aeruginosa PAO}

Total cellular protein was extracted from cells harvested during the exponential growth phase $\left(\mathrm{OD}_{650} 0.5\right)$, and separated by two-dimensional electrophoresis (Fig. 1) followed by silver staining. Visualization with ${ }^{35} \mathrm{~S}$ was not used, since there is evidence that proteins that are specifically induced under sulfate-limiting conditions may contain lower than average levels of cysteine and methionine (Hellinga \& Evans, 1985; Mazel \& Marliére, 1989), and would therefore only be poorly labelled by ${ }^{35} \mathrm{~S}$ compared to other cellular proteins. Computerassisted analysis of the gels revealed a set of $10 \mathrm{SSI}$ proteins which was partly or completely repressed whenever sulfate, thiocyanate or cysteine was present in the growth medium, but whose synthesis was upregulated during growth with all the other sulfur sources tested (Fig. 1, Table 3). The degree of up-regulation of each of the SSI proteins was measured by densitometric analysis (Table 3 ), and varied from $2 \cdot 2$-fold (protein PA7) to several proteins which could not be detected at all by silver staining after growth with sulfate.

To characterize the SSI proteins further, they were excised from the gels and their $\mathrm{N}$-terminal amino acid sequences were determined (Table 3). Using this method, protein PA1 could be identified with certainty as the sulfate-binding protein, since its $\mathrm{N}$-terminal sequence was $85 \%$ identical to that of the periplasmic sulfate-binding protein of $E$. coli, and its size and pI were also similar to those of the $E$. coli protein (Hellinga \& Evans, 1985). The sulfate-binding protein has not yet been reported in $P$. aeruginosa, but has been the subject of intensive study in E. coli (Jacobson et al., 1991) and in Salmonella typhimurium (Pflugrath \& Quiocho, 1985). In E. coli it has also been identified as an SSI protein using two-dimensional PAGE (Quadroni et al., 1996). Protein PA6 could not be analysed by the method used, 
since it could not be visualized by Coomassie staining, and protein PA8 was apparently N-terminally blocked. For protein PA11, $67 \%$ identity was found to the Nterminus of protein 40 from human liver (Hochstrasser et al., 1993). This protein is related to the large family of thiol-specific antioxidant proteins (Chae et al., 1994), which includes alkylhydroperoxide reductase, a protein whose synthesis was also shown to be partially controlled by sulfate in E. coli (Quadroni et al., 1996). The $\mathrm{N}$-terminal sequence of protein PA13 revealed $61 \%$ identity to the $\mathrm{N}$-terminus of the orfM gene product from Bacillus subtilis (Quirk et al., 1994), and 70\% identity to that of the Ssi6 protein in E. coli (Quadroni et al., 1996), both of unknown function. All of the remaining SSI proteins yielded sequences with no significant similarity to sequences in the databases.

To test whether the SSI proteins are general stress proteins, arylsulfatase activities and synthesis of the SSI proteins were measured under conditions of phosphate limitation $\left(0.2 \mathrm{mM}\right.$ phosphate), heat shock $\left(43^{\circ} \mathrm{C}\right)$ and during anaerobic growth. Sulfate-mediated repression of both arylsulfatase and SSI proteins was not overcome by any of the environmental stress signals tested.

\section{Synthesis of enzymes of sulfur metabolism by $P$. aeruginosa PAO during growth with different sulfur sources}

In E. coli, the SSI proteins have all proved to be involved in sulfur metabolism, and several play a role in the metabolism of organosulfur compounds (Quadroni et al., 1996; van der Ploeg et al., 1996; Eichhorn et al., 1997). In Pseudomonas species, by contrast, little is known about the sulfur assimilation pathway, and very few of the corresponding genes have been characterized. Since it seemed likely that the Pseudomonas SSI proteins might also be directly involved in sulfur metabolism, we measured the levels of several enzymes that play a role in cysteine or methionine biosynthesis during growth with a variety of sulfur sources (Table 2). Thiosulfate: cyanide sulfurtransferase (rhodanese) was chosen to represent a broad range of sulfurtransferases (Sörbo, 1975 ), cystathionine $\beta$-lyase plays a part in the methionine biosynthetic pathway, and cystathionine $\gamma$-lyase is important in cysteine biosynthesis in $P$. aeruginosa (Foglino et al., 1995). Arylsulfatase levels were also measured, since this enzyme has been used before as a marker enzyme for the sulfate starvation response (Beil et al., 1995; Kertesz et al., 1993). The results are shown in Table 2. In $P$. aeruginosa a high degree of repression was seen for arylsulfatase, but the other enzymes assayed displayed much less stringent control by sulfur supply. Significant levels of thiosulfate:cyanide sulfurtransferase activity could be measured, but the enzyme did not appear to be subject to repression by sulfate. The other enzymes examined showed up-regulation by a factor of up to threefold (cystathionine $\gamma$-lyase) and twoto fourfold (cystathionine $\beta$-lyase) in the absence of sulfate, significantly less than the up to 67 -fold induction seen for the arylsulfatase, or the de novo appearance of several of the SSI proteins seen on two-dimensional
PAGE (Fig. 1). Levels of cystathionine $\beta$-lyase observed were found to be significantly lower than those reported in E. coli (Uren, 1987), which may reflect the fact that this enzyme plays a less important role in $P$. aeruginosa than in the former organism, due to the presence of an alternative transsulfuration pathway leading directly to homocysteine (Foglino et al., 1995). Interestingly, the two lyases did not appear to be fully repressed by cysteine, though the presence of cysteine led to repression of the SSI stimulon (SSIS) and of arylsulfatase expression. This may suggest that cysteine and sulfate regulate different systems in this organism, or that cysteine does not play the key regulatory role in $P$. aeruginosa that it does in E. coli.

\section{Isolation of cysteine auxotrophic mutants of $P$. aeruginosa and characterization of the cysl and CysDN genes}

Although physiological studies have shown that the synthesis of arylsulfatase is repressed during growth with sulfate or cysteine (Beil et al., 1995), it was not yet known whether sulfate itself was responsible for this repression in vivo. To investigate this question, cysteine auxotrophic mutants of $P$. aeruginosa PAO1S were generated using the mini-Tn5-Tc system. After screening of 19200 mutants, 112 were found to be unable to grow on solid media with sulfate as sole sulfur source. Growth of these mutants was further characterized in liquid medium with sulfur supplied as sulfate, sulfite, pentanesulfonate, sulfide or cysteine. However, this physiological characterization was hampered by the fact that when cultivated with sulfate as sole sulfur source, many of the mutant strains reverted to a cysteine prototrophic phenotype after an 8-24 h lag phase. Southern analysis of selected strains revealed that the position of the transposon insertion in the revertants had remained stable (not shown), and we therefore concluded that the 'pseudoreversion' effect was due to selection for strains with suppressor mutations (see Discussion). We also observed suppression of the cysteine auxotrophic phenotype during cultivation with sulfate for two cysteine auxotrophic mutants which had been obtained previously, PAO716 and PAO1219 (O'Hoy, 1987; Ratnaningsih et al., 1990). The mutations in these latter strains have been mapped on the PAO chromosome to $56 \mathrm{~min}$ and $45 \mathrm{~min}$, respectively (Holloway et al., 1994), but it is not known in what genes the mutations are situated, nor have the mutants been further characterized biochemically.

For further work, we chose to use two of the isolated mutants, strains AC309 and AX18. On solid media, strain AX18 was unable to grow with sulfate, pentanesulfonate or sulfite, but grew well with sulfide or cysteine. This suggested that the strain was defective in sulfite reductase. Strain AC309 could grow with pentanesulfonate or sulfite, but not with sulfate, suggesting a defect in the sulfate activation pathway. This strain was also unable to grow with methionine, and there may therefore be a link between the sulfate activation pathway and the mechanism of methionine trans- 


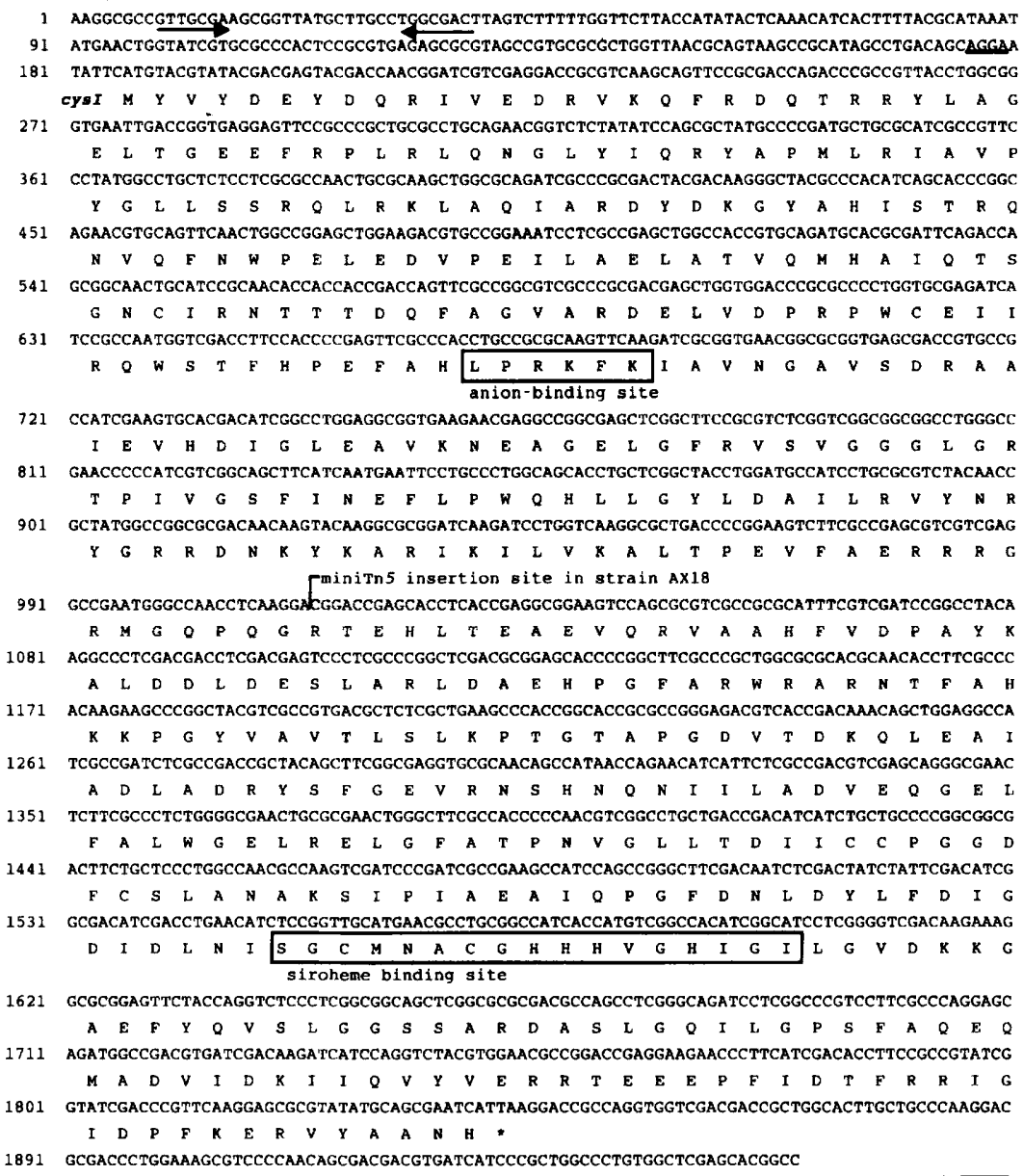

Fig. 2. DNA sequence of the cysl gene of $P$. aeruginosa, and the deduced amino acid sequence. The putative ribosome-binding site is underlined and the stop codon is shown with an asterisk. The proposed sirohaem binding site and anion-binding site are boxed, and a putative rhoindependent transcription terminator in the upstream region is shown with arrows. The site of mini-Tn5 insertion in strain AX18 is indicated. sulfuration in this species (Günther et al., 1979). Interestingly, both strains grew normally with thiocyanate, suggesting that thiocyanate-sulfur is not oxidized to sulfate before assimilation, but can enter the cysteine biosynthetic pathway directly, probably at the level of sulfide. Both strains were shown by Southern analysis to contain only a single transposon insertion.

To identify and characterize the interrupted loci in each of the two mutants, the insertion sites were cloned by transposon rescue techniques and the flanking regions were used to identify the corresponding clones in a $P$. aeruginosa library in the cosmid pLAFR3 (Visca et al., 1994). Sequencing of the transposon flanking regions in strain AX18 revealed an open reading frame encoding a $62 \mathrm{kDa}$ protein of pl $6 \cdot 3$, with $27 \%$ identity to the haemoprotein subunit of E. coli sulfite reductase (CysI). The protein included the typical $\mathrm{Fe}_{4} \mathrm{~S}_{4}$-sirohaem binding motif of sulfite and nitrite reductases (see Fig. 2), and also the conserved sequence LPRKFK, which has been associated with substrate anion binding in the $E$. coli sulfite reductase (Crane et al., 1995). Although the $E$. coli cysI gene is transcribed as part of the cysJIH operon, in $P$. aeruginosa it appeared to be monocystronic, since it was preceded by an inverted repeat and an AT-rich putative promoter region, and no further reading frames could be detected downstream. Interestingly, the $P$. aeruginosa cysH gene, which was recently described (Delic-Attree et al., 1997), also appears to be encoded as a single-gene transcript. Similar analysis of strain AC309 revealed that in this strain the transposon had inserted into an open reading frame encoding a $69.3 \mathrm{kDa}$ protein whose N-terminal domain showed $60 \%$ identity to the GTP-binding subunit of the E. coli ATP-sulfurylase protein (CysN). The C-terminal domain of this gene product showed high similarity to the product of the $E$. coli cys C gene, adenosine $5^{\prime}$-phosphosulfate kinase (Fig. 3 ), and the $P$. aeruginosa Cys $N$ protein therefore corresponds to an apparent functional fusion of the $E$. coli CysN and CysC proteins. Sequencing upstream and downstream of the $c y s N$ gene revealed that it was preceded by $c y s D$ (encoding a $35.5 \mathrm{kDa}$ protein with $78 \%$ identity to $E$. coli CysD), which encodes the small subunit of ATP-sulfurylase. The $c y s D$ and $c y s N$ genes of $P$. aeruginosa therefore appear to encode a single enzyme complex responsible for sulfate activation in this species. Divergent to $c y s D$ lay the start of a further open reading frame, orf $\mathrm{X}$, with similarity to the $E$. coli mlt $B$ gene. The $\mathrm{mol} \% \mathrm{G}+\mathrm{C}$ content of the $c y s I$ and $c y s D N$ coding regions (65\% and $64 \%$, respectively) was slightly lower than that normally seen for $P$. aeruginosa (West $\&$ Iglewski, 1988) but agreed well with the $64 \mathrm{~mol} \% \mathrm{G}+\mathrm{C}$ content found for other cysteine biosynthetic genes in this species (Delic-Attree et al., 1997). 
P. aeruginosa CysN

E. Coli CysN

E. $\operatorname{coli}$ CysC

P. aeruginosa CysN

E. Coli CysN

E. coli CysC

P. aeruginosa CysN

E. coli CysN

E. coli CysC

P. aeruginosa CysN

E. coli CysN

E. coli CysC

P. aeruginosa CysN

E. coli CysN

E. coli CysC

P. aeruginosa CysN

E. coli CysN

E. coll CysC

P. aeruginosa CysN

E. Coli CysN

E. coli cysC

P. aeruginosa CysN

E. Coli CysN

E. coli CysC
1

...MSHOSDL ISEDILAYLG OHERKELLRF ITCGNYDDGK STLIGRLLHD SKMIYEDHLE AITRDSKKYG TTGDDVDLAL IVDGIOAERE MNTALAQQIA NEGGVEAWMI AQQHKSLLRF LTCGSVDDGK STLIGRLLHD TRQIYEDQLS SLHNDSKRHG TQGEKLDLAL LVDGLQAERE

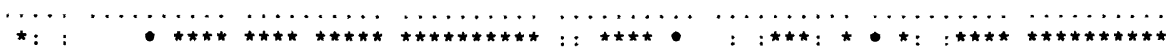

91

180

QGITIDVAYR YFSTAKRKFI IADTPGHEQY TRNMATGAST CDLAIILIDA RYGVOTQTRR HSFIASLLGI RHIVVAINKM DLKDFDQGVF QGITIDVAYR YFSTEKRKFI IADTPGHEQY TRNMATGAST CELAILLIDA RKGVLDQTRR HSFISTLLGI KHLVVAINKM DLVDYSEETF

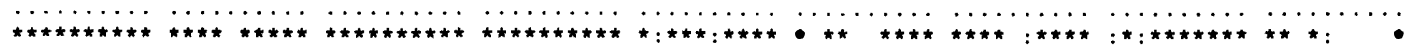

181

270

EQIKADYLAF AEKIGLKTSS LHFVPMSALK GDNVVNKSER SPWYAGQSLM EILETVEIAA DRNLDDMRFP VQYVNRPNLN FRGFAGTLAS TRIREDYLTF AGQLPGNL.D IRFVPLSALE GDNVASQSES MPWYSGPTLL EVLETVEIQR VVDAQPMRFP VQYVNRPNLD FRGYAGTLAS

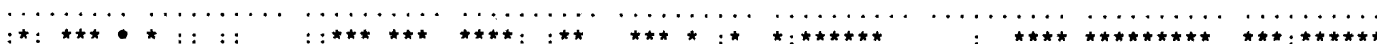
271

360 GVVRKGDEVV ALPSGKGSKV KSIVTFEGEL EQAGPGQAVT LTLEDEIDVS RGDMLVHADN RPLVTDGFDA MLVWMAEEPM LPGKKYDIKR GRVEVGQRVK VLPSGVESNV ARIVTEDGDR EEAFAGEAIT LVLTDEIDIS RGDLLLAADE ALPAVQSASV DVVWMAEQPL SPGQSYDIKI

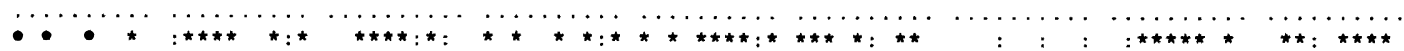

361

450 ATSYVPGSIP SIVHKVDVNT LERTPGSELK LNEIARVKVS LDAPIALDGY EQNRTTGAFI VIDRLTNGTV GAGMIVSAPP AAHGSSAHHG AGKKTRARVD GIRYQVDINN LTQREVENLP LNGIGLVDLT FDEPLVLDRY QQNPVTGGLI FIDRLSNVTV GAGMVHEPVS QATAAPSEFS

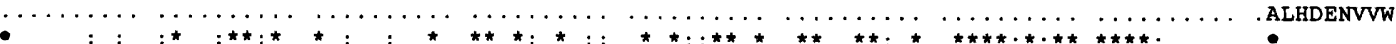

451

540

SNAHVTREER AGRFGQQPAT VLFSGLSGAG KSTLAYAVER KLFDMGRAVY VLDGQNLRHD LNKGLPQDRA GRTENWLRTA HVAKQFNEAG

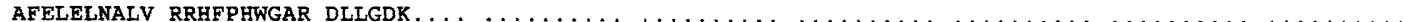
HSHPVTVQQR ELHHGHRGVV LWFTGLSGSG KSTVAGALEE ALHKLGVSTY LLDGDNVRHG LCSDLGFSDA DRKENIRRVG EVANLMVEAG

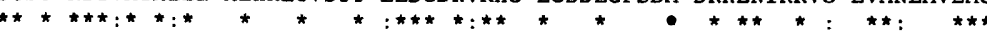

541

541
LISLCAFVAP SAEGREQARA LIGAERLITV YVQASPQVCR ERDPQGLY.. A.AGE.DNIP GESFPYDVPL DADLVIDTQA LSVEDGVKQV

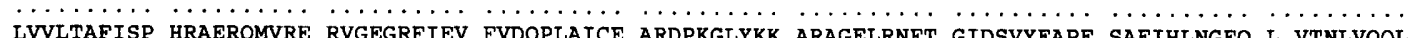

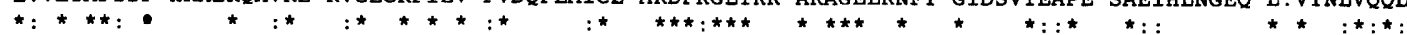

631642

LDLLRERQAI

$\ldots \ldots . . . . .$.

LDLLRQNDII R

Fig. 3. Sequence alignment of the product of the $P$. aeruginosa cys $N$ gene with the $E$. coli Cys $N$ and CysC proteins, showing the two-domain structure of the $P$. aeruginosa CysN protein. The alignment was done with the program PILEUP. Residues which are identical (*) and similar (:) in both sequences are indicated.

\section{Chromosomal location of the cysl and cysDN genes}

The cysI and cysDN genes were localized on the chromosome of $P$. aeruginosa PAO by hybridization of digoxigenin-labelled probes to genomic DNA digested with SpeI or DpnI as described previously by Römling et al. (1992). The cysI gene hybridized to SpeI fragment L and $D p n I$ fragment $\mathrm{C}$, corresponding to the $55-57.5 \mathrm{~min}$ region of the chromosome, where the cys-54 and cysG1 loci have previously been located (Holloway et al., 1994). The cysDN genes hybridized to SpeI fragment E and $D p n \mathrm{I}$ fragment I, corresponding to the $71-75 \mathrm{~min}$ region.

\section{Regulation of the sulfate starvation response in cysteine auxotrophic mutants of $P$. aeruginosa}

The regulation of the sulfate starvation response was investigated in the mutant strains AX18 and AX309, initially by using arylsulfatase activity as a marker for the two-dimensional PAGE response. Cells were grown with a derepressing sulfur source (methionine for strains PAO1S and AX18 and pentanesulfonate for strain
AC309, since the latter strain did not grow with methionine), and arylsulfatase activities were measured in the exponential phase. Low-molecular-mass sulfur compounds (sulfate, sulfite, sulfide, thiocyanate) were added to the growth medium to test their effect as repressors of ats $A$ expression (Fig. 4), and control experiments were included to check that the pseudoreversion effect described above did not occur in the time frame of the experiment. In the wild-type strain, arylsulfatase expression was completely repressed by sulfate, sulfite, sulfide or thiocyanate, as expected. In AC309, which is unable to activate sulfate and reduce it to sulfite, sulfate no longer repressed ats $A$ expression, showing clearly that sulfate is not the active corepressor in vivo. Sulfite, sulfide and thiocyanate repressed ats $A$ expression in all three strains. Since strain AX18 cannot convert sulfite to sulfide, this implies that separate effects are responsible for the repressive nature of these two compounds. Two-dimensional PAGE gels were also prepared with extracts of the PAO1S, AX18 and AC309 cultures used for the arylsulfatase assays. Under the growth conditions tested, synthesis of the SSI proteins 


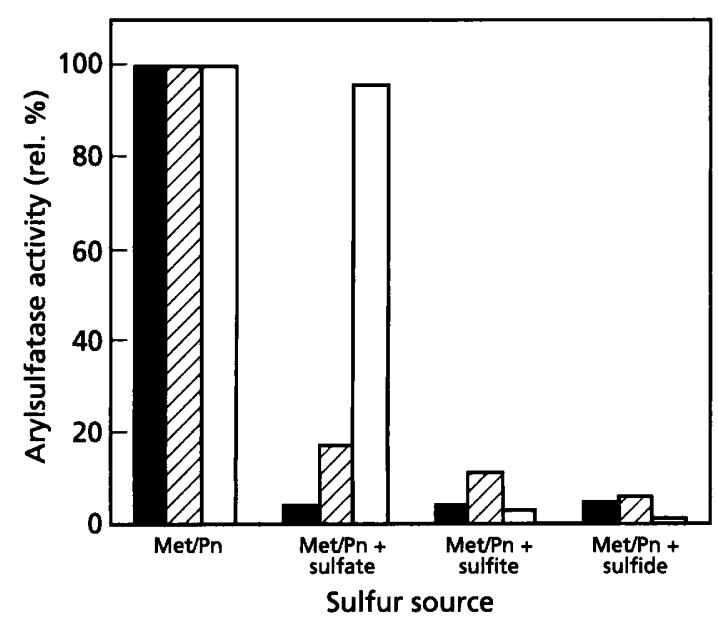

Fig. 4. Arylsulfatase activities in cysl and cys $N$ strains of $P$. aeruginosa. Cells were cultivated with methionine (strains AX18, PAO1S) or pentanesulfonate (strain AC309) as sulfur source $(100 \mu \mathrm{M})$, and sulfate, sulfite or sulfide $(500 \mu \mathrm{M})$ was added. Arylsulfatase activity was assayed in whole cells and is given as a percentage of the value observed after growth with methionine or pentanesulfonate [Met/Pn; $14-20 \mathrm{nmol} \mathrm{min}^{-1}$ (mg protein) $)^{-1}$. $\square$, Strain PAO1S; 댐, strain AX18 (cys); $\square$, strain AC309 (cysN).

described above (Table 3) was controlled in exactly the same way as that of arylsulfatase, even though the latter was present at too low a level to be visible on the twodimensional gels (Beil et al., 1995). Intermediate levels of arylsulfatase activity (e.g. with strain AX18 after growth with sulfate/methionine; Fig. 4) gave rise to SSI protein spots on the gels of reduced intensity (not shown). We conclude that at least two separate corepressors exist to mediate repression of the sulfate starvation response, one located before and one after sulfite in the cysteine biosynthetic pathway.

\section{DISCUSSION}

Synthesis of at least 10 proteins is regulated in $P$. aeruginosa by the sulfur supply during steady state growth (SSI proteins; Fig. 1, Table 3). This number represents a minimum value, since enzymes involved in sulfur metabolism are only required at low levels (sulfur constitutes $0.5 \%$ of dry weight in Pseudomonas cells; Kertesz et al., 1993), and many more may be expressed at concentrations below the detection limit of the conditions used in this study. This is the case for arylsulfatase, where the enzyme constitutes only $0.04 \%$ of cell protein even when fully induced, and is not visible in two-dimensional PAGE of cell extracts (Beil et al., 1995). Although sulfur-limiting conditions could in principle lead to induction of the stringent response (Cashel et al., 1996), the doubling times for P. aeruginosa were comparable for all the sulfur sources we examined (Table 2) and we concluded that the increased synthesis of the SSI proteins was not part of a general starvation response, but due to repression exerted by sulfite, cysteine or thiocyanate, or a related metabolite. The identification of Sbp as one of the SSI proteins in $P$. aeruginosa (Table 3) confirms that the SSI proteins include sulfur-scavenging proteins in this species, and hence the unidentified SSI proteins might include enzyme systems for assimilation of alternative sulfur sources such as alkanesulfonates (Kertesz, 1996; Kertesz et al., 1994) or arylsulfates (Beil et al., 1995). For further studies of the SSI proteins we are using the sequences obtained (Table 3) to isolate the corresponding genes, and hope thereby to arrive at a fuller understanding of the functions of these proteins.

The broad range of sulfur sources which $P$. aeruginosa can assimilate was divided into two groups on the basis of repression or derepression of the SSI proteins (Table 2). This division is reminiscent of previous classifications of sulfur sources into 'preferred' and 'non-preferred' compounds in other species [e.g. E. coli (Roberts et al., 1955; Uria-Nickelsen et al., 1994), Comamonas (Seitz et al., 1993), Pseudomonas putida (Beil et al., 1996)]. For $P$. putida, detailed growth measurements have shown that the sulfur sources that repress the SSIS are also utilized preferentially by the cell (Beil et al., 1996). This represents an exact parallel to other nutrient starvation systems - in the case of phosphorus, for example, it is the absence of the preferred phosphorus source (inorganic phosphate) which leads to synthesis of the proteins that constitute the pho regulon. Whether the analogy between these two systems ( $p h o$ and SSIS) can be extended further is not yet clear, since the pho system is essentially regulated only by phosphate levels (Wanner, 1993), whereas the SSIS in P. aeruginosa is repressed by sulfate, cysteine and thiocyanate. Up until now thiocyanate has primarily been explored as a source of carbon (Boucabeille et al., 1994), energy (Katayama et al., 1995) or nitrogen (Betts et al., 1979; Stratford et al., 1994) for bacteria, and very few data are available on its utilization as a sulfur source (Laudenbach \& Grossman, 1991). Although the mechanism by which thiocyanatesulfur is assimilated has not yet been elucidated, our results suggest that the sulfur atom enters the cysteine biosynthetic pathway at the level of sulfide, possibly by direct sulfo transfer to an acceptor such as acetylserine or succinylhomoserine.

The chemical and structural diversity of the SSISrepressing substrates poses the interesting mechanistic question of whether all of these substrates are active as corepressors in vivo, whether they are interconverted, or whether regulation is effected by conversion to a single, as yet unidentified effector. The best characterized system that is regulated by sulfur is the cys regulon (Kredich, 1996), whose components are also repressed by cysteine and sulfate. Nothing is known of the effect of thiocyanate, but most studies of the cys regulon have been done in $E$. coli, which does not use thiocyanate as a sulfur source (Kertesz et al., 1993). For the cys regulon, dual regulation by cysteine and sulfate may be traced to two effects - feedback regulation by cysteine to prevent synthesis of the positive effector $\mathrm{N}$-acetylserine, and conversion of sulfate to sulfide, which exerts an antiinduction effect on several genes of the regulon (Kredich, 1996). A different type of mechanism has been reported 
for arylsulfatase synthesis by Klebsiella pneumoniae. In this organism, studies with cysteine biosynthesis mutants have shown that sulfate can act to repress arylsulfatase synthesis without prior activation and reduction, and that cysteine acts as a corepressor independently from sulfate (Adachi et al., 1975). Our results with mutants of $P$. aeruginosa (Fig. 4) suggest another mode of regulation. As in $K$. pneumoniae, at least two sulfur-containing species can act as corepressors, but intracellular sulfate itself is not active as a corepressor molecule. This, and the results of enzyme measurements reported above (Table 2) suggest that for sulfur assimilation several regulatory circuits may overlap, and the regulatory situation may be more complex than previously thought.

One of the proteins identified as part of the SSIS in $P$. aeruginosa, the periplasmic sulfate-binding protein $(\mathrm{Sbp})$, is also a member of the cys regulon in enteric bacteria (Kredich, 1996), and is especially important in scavenging sulfate at low concentrations. Since $s b p A$ mutants of Synechococcus can still utilize sulfate (Laudenbach \& Grossman, 1991), the Sbp protein is clearly not always required for sulfate transport, and it may constitute a second, high-affinity sulfate-uptake system in this species, analogous to the Pst system for phosphate uptake (Wanner, 1993). A similar duplication of function is also seen with the Sbp protein and the thiosulfate-binding protein in E. coli (Sirko et al., 1995). We and others (Calhoun \& Feary, 1969) have had difficulty isolating $P$. aeruginosa mutants in some loci of the cys pathway (e.g. sulfate uptake), and this and the rapid appearance of pseudorevertants of our cys mutants suggest that several of the cys genes may be duplicated on the chromosome. Duplication of cys gene activities has been reported for Salmonella, for CysI, CysB and CysM activities. In this species, specific expression of the pairs of homologues is controlled by the oxygen status of the cells (Kredich, 1996). In P. aeruginosa, genes involved in cysteine and methionine biosynthesis are quite scattered, being located at 20 and 40 min (methionine biosynthesis), and at 45, 56, 69 and 71-75 $\mathrm{min}$ (cysteine biosynthesis) on the PAO chromosome. Three genes have been characterized at a DNA sequence level until now - met $Z$ (O-succinylhomoserine sulfhydrylase; Foglino et al., 1995), cysH (phosphoadenosinephosphosulfate sulfotransferase; Delic-Attree et al., 1997) and the regulatory gene $c y s B$, which also appears to play a role in alginate biosynthesis in this species (Delic-Attree et al., 1997). More work is clearly required on cysteine and methionine biosynthesis in $P$. aeruginosa, since several differences to the pathways that have been characterized in E. coli are already apparent, both at a biochemical level (Foglino et al., 1995; Günther et al., 1979) and at the level of gene organization (DelicAttree et al., 1997; this paper).

\section{ACKNOWLEDGEMENTS}

We are indebted to K. Schmidt for carrying out the chromosomal mapping experiments. We are grateful to A. M. Cook, P. James and P. Vermeij for helpful discussions, and to L.
Serino for providing the gene bank. This work was supported in part by Swiss National Science Foundation grant no. 3141873.94 (J.H.).

\section{REFERENCES}

Adachi, T., Murooka, Y. \& Harada, T. (1975). Regulation of arylsulfatase synthesis by sulfur compounds in Klebsiella aerogenes. J Bacteriol 121, 29-35.

Ausubel, F. M., Brent, R., Kingston, R. E., Moore, D. E., Seidman, J. G., Smith, J. A. \& Struhl, K. (1987). Current Protocols in Molecular Biology. New York: Wiley.

Autry, A. R. \& Fitzgerald, J. W. (1990). Sulfonate $S$ - a major form of forest soil organic sulfur. Biol Fertil Soils 10, 50-56.

Beil, S., Kehrli, H., James, P., Staudenmann, W., Cook, A. M., Leisinger, T. \& Kertesz, M. A. (1995). Purification and characterization of the arylsulfatase synthesized by Pseudomonas aeruginosa PAO during growth in sulfate-free medium and cloning of the arylsulfatase gene (atsA). Eur J Biochem 229, 385-394.

Beil, S., Kertesz, M. A., Leisinger, T. \& Cook, A. M. (1996). The assimilation of sulfur from multiple sources and its correlation with expression of the sulfate-starvation-induced stimulon in Pseudomonas putida S-313. Microbiology 142, 1989-1995.

Betts, P. M., Rinder, D. F. \& Flecker, J. R. (1979). Thiocyanate utilization by an Arthrobacter. Can J Microbiol 25, 1277-1282.

Boucabeille, C., Bories, A. \& Olivier, P. (1994). Degradation of thiocyanate by a bacterial coculture. Biotechnol Lett 16, 425-430.

Calhoun, D. H. \& Feary, T. W. (1969). Transductional analysis of Pseudomonas aeruginosa methionineless auxotrophs. $J$ Bacteriol 97, 210-216.

Cashel, M., Gentry, D. R., Hernandez, V. J. \& Vinella, D. (1996). The stringent response. In Escherichia coli and Salmonella, pp. 1458-1496. Edited by F. C. Neidhardt and others. Washington: American Society for Microbiology.

Chae, H. Z., Robison, K., Poole, L. B., Church, G., Storz, G. \& Rhee, S. G. (1994). Cloning and sequencing of thiol-specific antioxidant from mammalian brain : alkyl hydroperoxide reductase and thiolspecific antioxidant define a large family of antioxidant enzymes. Proc Natl Acad Sci USA 91, 7017-7021.

Crane, B. R., Siegel, L. M. \& Getzoff, E. D. (1995). Sulfite reductase structure at $1.6 \AA$ : evolution and catalysis for reduction of inorganic anions. Science 270, 59-67.

Delic-Attree, I., Toussaint, B., Garin, J. \& Vignais, P. M. (1997). Cloning, sequence and mutagenesis of the structural gene of Pseudomonas aeruginosa $\mathrm{CysB}$, which can activate algD transcription. Mol Microbiol 24, 1275-1284.

De Lorenzo, V. \& Timmis, K. N. (1994). Analysis and construction of stable phenotypes in gram-negative bacteria with Tn5- and Tn10-derived minitransposons. Methods Enzymol 235, 386-405.

Dodgson, K. S., White, G. F. \& Fitzgerald, J. W. (1982). Sulfatases of Microbial Origin. Boca Raton, FL: CRC Press.

Dudley, M. W. \& Frost, J. W. (1994). Biocatalytic desulfurization of arylsulfonates. Bioorg Med Chem 2, 681-690.

Eichhorn, E., van der Ploeg, J. R., Kertesz, M. \& Leisinger, T. (1997). Characterization of $\alpha$-ketoglutarate-dependent taurine dioxygenase from Escherichia coli. J Biol Chem 272, 23031-23036.

Foglino, M., Borne, F., Bally, M., Ball, G. \& Patte, J. C. (1995). A direct sulfhydrylation pathway is used for methionine biosynthesis in Pseudomonas aeruginosa. Microbiology 141, 431-439.

Gunther, E., Petruschka, L. \& Herrmann, H. (1979). Reverse 
transsulfuration pathway in Pseudomonas aeruginosa. Z Allg Mikrobiol 19, 439-442.

Hanahan, D. (1983). Transformation of Escherichia coli with plasmids. J Mol Biol 166, 557-580.

Harvey, N. L., Fewson, C. A. \& Holms, W. H. (1968). Apparatus for batch culture of micro-organisms. Lab Pract 1968, 1134-1136.

Hatt, P. D., Quadroni, M., Staudenmann, W. \& James, P. (1997). Concentration of, and SDS removal from proteins isolated from multiple two dimensional electrophoresis gels. Eur $J$ Biochem 246, 336-343.

Hellinga, H. W. \& Evans, P. R. (1985). Nucleotide sequence and high-level expression of the major Escherichia coli phosphofructokinase. Eur J Biochem 149, 363-373.

Hochstrasser, D. F., Harrington, M. G., Hochstrasser, A. C., Miller, M. J. \& Merril, C. R. (1988). Methods for increasing the resolution of two-dimensional protein electrophoresis. Anal Biochem 173, 424-435.

Hochstrasser, D. F, Frutiger, S., Paquet, N. \& 9 other authors (1993). Human liver reference map: a reference database established by microsequencing and gel comparison. Electrophoresis 13, 992-1001.

Holloway, B. (1955). Genetic recombination in Pseudomonas aeruginosa. J Gen Microbiol 13, 572-581.

Holloway, B. W., Römling, U. \& Túmmler, B. (1994). Genomic mapping of Pseudomonas aeruginosa PAO. Microbiology 140, 2907-2929.

Inoue, H., Nojima, H. \& Okayama, H. (1990). High efficiency transformation of Escherichia coli with plasmids. Gene 96, 23-28.

Jacobson, B. L., Het, J. J., Vermersch, P. S., Lemon, D. D. \& Quiocho, F. A. (1991). Engineered interdomain disulfide in the periplasmic receptor for sulfate transport reduces flexibility. $J$ Biol Chem 266, 5220-5225.

Katayama, Y., Hiraishi, A. \& Kuraishi, H. (1995). Paracoccus thiocyanatus sp. nov., a new species of thiocyanate-utilizing facultative chemolithotroph, and transfer of Thiobacillus versutus to the genus Paracoccus as Paracoccus versutus comb. nov. with emendation of the genus. Microbiology 141, 1469-1477.

Kayser, K. J., Bielaga-Jones, B. A., Jackowski, K., Odusan, O. \& Kilbane, J. J. (1993). Utilization of organosulphur compounds by axenic and mixed cultures of Rhodococcus rhodochrous IGTS8. J Gen Microbiol 139, 3123-3129.

Kennedy, S. I. T. \& Fewson, C. A. (1968). Enzymes of the mandelate pathway in the bacterium NCIB 8250. Biochem $J 107$, 497-506.

Kertesz, M. A. (1996). Desulfonation of aliphatic sulfonates by Pseudomonas aeruginosa PAO. FEMS Microbiol Lett 137, 221-225.

Kertesz, M. A., Leisinger, T. \& Cook, A. M. (1993). Proteins induced by sulfate limitation in Escherichia coli, Pseudomonas putida, or Staphylococcus aureus. J Bacteriol 175, 1187-1190.

Kertesz, M. A., Kölbener, P., Stockinger, H., Beil, S. \& Cook، A. M. (1994). Desulfonation of linear alkylbenzenesulfonate surfactants and related compounds by bacteria. Appl Environ Microbiol 60, 2296-2303.

Kredich, N. M. (1996). Biosynthesis of cysteine. In Escherichia coli and Salmonella, pp. 514-527. Edited by F. C. Neidhardt and others. Washington: American Society for Microbiology.

Laudenbach, D. E. \& Grossman, A. (1991). Characterization and mutagenesis of sulfur-regulated genes in a cyanobacterium: evidence for function in sulfate transport. J Bacteriol 173, 2739-2750.
Leustek, T. (1996). Molecular genetics of sulfate assimilation in plants. Physiol Plant 97, 411-419.

Mazel, D. \& Marliére, P. (1989). Adaptive eradication of methionine and cysteine from bacterial light-harvesting proteins. Nature 341, 245-248.

Nagasawa, T., Kanzaki, H. \& Yamada, H. (1987). Cystathionine gamma-lyase from Streptomyces phaeochromogenes. Methods Enzymol 143, 486-493.

O'Hoy, K. (1987). Genetic and physical analysis of the Pseudomonas aeruginosa chromosome. $\mathrm{PhD}$ thesis, Monash University.

Pflugrath, J. W. \& Quiocho, F. A. (1985). Sulphate sequestered in the sulphate-binding protein of Salmonella typhimurium is bound solely by hydrogen bonds. Nature 314, 257-260.

van der Ploeg, J. R., Weiss, M. A., Saller, E., Nashimoto, H., Saito, N., Kertesz, M. A. \& Leisinger, T. (1996). Identification of sulfate starvation-regulated genes in Escherichia coli: a gene cluster involved in the utilization of taurine as a sulfur source. J Bacteriol 178, 5438-5446.

Quadroni, M., Staudenmann, W., Kertesz, M. \& James, P. (1996). Analysis of global responses by protein and peptide fingerprinting of proteins isolated by two-dimensional gel electrophoresis. Eur J Biochem 239, 773-781.

Quirk, P. G., Guffanti, A. A., Clejan, S., Cheng, J. \& Krulwich, T. A. (1994). Isolation of Tn917 insertional mutants of Bacillus subtilis that are resistant to the protonophore carbonyl cyanide $m$ chlorophenylhydrazone. Biochim Biophys Acta 1186, 27-34.

Ratnaningsih, E., Dharmsthiti, S., Krishnapillai, V., Morgan, A., Sinclair, M. \& Holloway, B. W. (1990). A combined physical and genetic map of Pseudomonas aeruginosa PAO. J Gen Microbiol 136, 2351-2357.

Roberts, R. B., Abelson, P. H., Cowie, D. B., Bolton, E. T. \& Britten, R. J. (1955). Studies of Biosynthesis in Escherichia coli. Washington, DC: Carnegie Institution.

Römling, U., Duchêne, M., Essar, D. W. \& 9 other authors (1992). Localization of alg, opr, phn, pho, 4.5S RNA, 6S RNA, tox, trp and $x c p$ genes, $r r n$ operons and the chromosomal origin on the physical genome map of Pseudomonas aeruginosa PAO. J Bacteriol 174, 327-330.

Sanger, F., Nicklen, S. \& Coulson, A. R. (1977). DNA sequencing with chain-terminating inhibitors. Proc Natl Acad Sci USA 74, 5463-5467.

Seitz, A. P., Leadbetter, E. R. \& Godchaux, W., III (1993). Utilization of sulfonates as sole sulfur source by soil bacteria including Comamonas acidovorans. Arch Microbiol 159, 440-444.

Sirko, A., Zatyka, M., Sadowy, E. \& Hulanicka, D. (1995). Sulfate and thiosulfate transport in Escherichia coli K-12: evidence for a functional overlapping of sulfate- and thiosulfate-binding proteins. J Bacteriol 177, 4134-4136.

Sörbo, B. (1975). Thiosulfate sulfur transferase and mercaptopyruvate sulfur transferase. In Metabolic Pathways, vol. 7: Metabolism of Sulfur Compounds, pp. 433-456. Edited by D. M. Greenberg. New York: Academic Press.

Staskawicz, B., Dahlbeck, D., Keen, N. \& Napoli, C. (1987). Molecular characterization of cloned avirulence genes from race 0 and race 1 of Pseudomonas syringae pv. glycinea. J Bacteriol 169, 5789-5794.

Stratford, J., Dias, A. E. X. O. \& Knowles, C. J. (1994). The utilization of thiocyanate as a nitrogen source by a heterotrophic bacterium: the degradative pathway involves formation of ammonia and tetrathionate. Microbiology 140, 2657-2662.

Strickland, T. C., Fitzgerald, J. W. \& Swank, W. T. (1986). In situ 
measurements of sulfate incorporation into forest floor and soil organic matter. Can J For Res 16, 549-553.

Uren, J. R. (1987). Cystathionine beta-lyase from Escherichia coli. Methods Enzymol 143, 483-486.

Uria-Nickelsen, M. R., Leadbetter, E. R. \& Godchaux, W., III (1994), Comparative aspects of utilization of sulfonate and other sulfur sources by Escherichia coli K12. Arch Microbiol 161, 434-438.

Visca, P., Ciervo, A. \& Orsi, N. (1994). Cloning and nucleotide sequence of the pvdA gene encoding the pyoverdin biosynthetic enzyme L-ornithine N5-oxygenase in Pseudomonas aeruginosa. J Bacteriol 176, 1128-1140.

Wanner, B. L. (1993). Gene regulation by phosphate in enteric bacteria. J Cell Biochem 51, 47-54.
Watwood, M. E., Fitzgerald, J. W. \& Gosz, J. R. (1986). Sulfur processing in forest soil and litter along an elevational and vegetative gradient. Can J For Res 16, 689-695.

West, S. E. \& Iglewski, B. H. (1988). Codon usage in Pseudomonas aeruginosa. Nucleic Acids Res 16, 9323-9325.

Westley, J. (1981). Thiosulfate: cyanide sulfurtransferase (rhodanese). Methods Enzymol 77, 285-291.

Zürer, D., Cook, A. M. \& Leisinger, T. (1987). Microbial desulfonation of substituted naphthalenesulfonic acids and benzenesulfonic acids. Appl Environ Microbiol 53, 1459-1463.

Received 30 September 1997; revised 26 November 1997; accepted 6 January 1998 